ORIGINAL ARTICLE

\section{Smoke-free Legislation and Hospitalizations for Childhood Asthma}

\author{
Daniel Mackay, Ph.D., Sally Haw, B.Sc., Jon G. Ayres, M.D., \\ Colin Fischbacher, M.B., Ch.B., and Jill P. Pell, M.D.
}

A BSTRACT

\section{BACKGROUND}

Previous studies have shown that after the adoption of comprehensive smoke-free legislation, there is a reduction in respiratory symptoms among workers in bars. However, it is not known whether respiratory disease is also reduced among people who do not have occupational exposure to environmental tobacco smoke. The aim of our study was to determine whether the ban on smoking in public places in Scotland, which was initiated in March 2006, influenced the rate of hospital admissions for childhood asthma.

\section{METHODS}

Routine hospital administrative data were used to identify all hospital admissions for asthma in Scotland from January 2000 through October 2009 among children younger than 15 years of age. A negative binomial regression model was fitted, with adjustment for age group, sex, quintile of socioeconomic status, urban or rural residence, month, and year. Tests for interactions were also performed.

\section{RESULTS}

Before the legislation was implemented, admissions for asthma were increasing at a mean rate of $5.2 \%$ per year ( $95 \%$ confidence interval [CI], 3.9 to 6.6). After implementation of the legislation, there was a mean reduction in the rate of admissions of $18.2 \%$ per year relative to the rate on March 26, 2006 (95\% CI, 14.7 to 21.8; $\mathrm{P}<0.001)$. The reduction was apparent among both preschool and school-age children. There were no significant interactions between hospital admissions for asthma and age group, sex, urban or rural residence, region, or quintile of socioeconomic status.

\section{CONCLUSIONS}

In Scotland, passage of smoke-free legislation in 2006 was associated with a subsequent reduction in the rate of respiratory disease in populations other than those with occupational exposure to environmental tobacco smoke. (Funded by NHS Health Scotland.)
From the Section of Public Health, University of Glasgow, Glasgow (D.M., J.P.P.), Scottish Collaboration on Public Health Research Policy, Edinburgh (S.H.), Institute of Occupational and Environmental Medicine, University of Birmingham, Birmingham (J.G.A.), and Information Services Division, NHS National Services, Edinburgh (C.F.) - all in the United Kingdom. Address reprint requests to Dr. Pell at Public Health Section, University of Glasgow, Rm. 305, 1 Lilybank Gardens, Glasgow G12 8RZ, United Kingdom, or at j.pell@clinmed gla.ac.uk.

N Engl J Med 2010;363:1139-45.

Copyright (๐) 2010 Massachusetts Medical Society. 
T HE PREVALENCE OF ASTHMA HAS INcreased over the past few decades. ${ }^{1}$ Active smoking is much less common among children than among adults. In Scotland, $25 \%$ of adults smoke, ${ }^{2}$ as compared with only $4 \%$ of 13 -year-olds and $15 \%$ of 15 -year-olds. ${ }^{3}$ However, children are commonly exposed to environmental tobacco smoke, particularly in the home. Studies in Scotland and in the United States have shown that $40 \%$ of 11 -year-old children ${ }^{4}$ and 5-year-old children $^{5}$ live with a smoker. Exposure to environmental tobacco smoke increases the incidence and severity of asthma, ${ }^{6}$ and children are particularly susceptible to the deleterious effects of such exposure. ${ }^{7}$ In the United States, more than 200,000 episodes of childhood asthma per year have been attributed to parental smoking. ${ }^{8}$

In Scotland, the Smoking, Health and Social Care (Scotland) Act banned smoking in all enclosed public places and workplaces as of March 26, 2006. The legislation has been extremely successful in its primary aim of reducing exposure to environmental tobacco smoke in public places, such as bars.9,10 As a result, there has been a reduction in respiratory symptoms among workers in bars - even among workers who continue to smoke themselves. ${ }^{11}$ Initial concerns that the legislation would increase smoking in homes have not been realized. Rather, the legislation has resulted in a greater adoption of voluntary bans on smoking in homes ${ }^{12}$ and a reduction in the overall exposure of children to environmental tobacco smoke. ${ }^{4}$ The aim of this study was to determine whether the risk of a hospital admission for childhood asthma has changed since the introduction of comprehensive smoke-free legislation in Scotland.

METHODS

DATA SOURCES AND EXCLUSION CRITERIA

Scotland has a population of approximately 5.1 million. The Scottish Morbidity Record (SMR01) collects information on all admissions to acute care hospitals in Scotland, including the date of the admission, the type of admission, the principal and secondary disease codes, and the patient's age, sex, and data zone (a Scottish postal code) of residence. The General Register Office for Scotland collects death-certificate data on all deaths that occur in Scotland, whether they oc- cur in a hospital or in the community. The deathcertificate data include the date of death, the primary underlying cause of death, and the patient's age, sex, and data zone of residence. Both databases classify diseases according to the International Classification of Diseases, 10th Revision (ICD10). The admission and death databases are linked at an individual level so that records relating to the same person can be identified. We used the SMR01 database to identify all admissions for asthma that occurred in Scotland from January 2000 through October 2009. We also combined SMR01 and death-certificate data to identify all hospital admissions and deaths before arrival at the hospital that occurred during the same period.

\section{DEFINITIONS}

We defined admissions for asthma as emergency hospital admissions for a principal diagnosis of asthma, irrespective of whether the patient was discharged alive or died in the hospital. We defined asthma events as admissions for asthma plus deaths due to asthma that occurred before arrival at the hospital. In-hospital death after admission for asthma was counted as a single event. Asthma was defined as an ICD-10 disease code of J45 or J46. We defined preschool-age children as children 0 to 4 years of age at the time of the event and school-age children as children 5 to 14 years of age. Socioeconomic status was categorized into quintiles on the basis of the Scottish Index of Multiple Deprivation (SIMD) 2006 for the data zone of residence (www.scotland.gov .uk/Topics/Statistics/SIMD/Overview). Categorization into urban and rural residency was derived from the data zone of residence and was based on the Scottish Executive Urban Rural Classification system (www.scotland.gov.uk/Resource/ Doc/47251/0028898.pdf). Large urban areas and other urban areas were coded as urban, and all other areas were coded as rural. Three regions of residence were defined on the basis of health board areas of residence: southwestern Scotland comprised the Ayrshire, Greater Glasgow and Clyde, Dumfries and Galloway, and Lanarkshire health boards; southeastern Scotland comprised the Lothian, Borders, and Forth Valley health boards, and northern Scotland comprised the Grampian, Highland, Tayside, Fife, and Island health boards. 


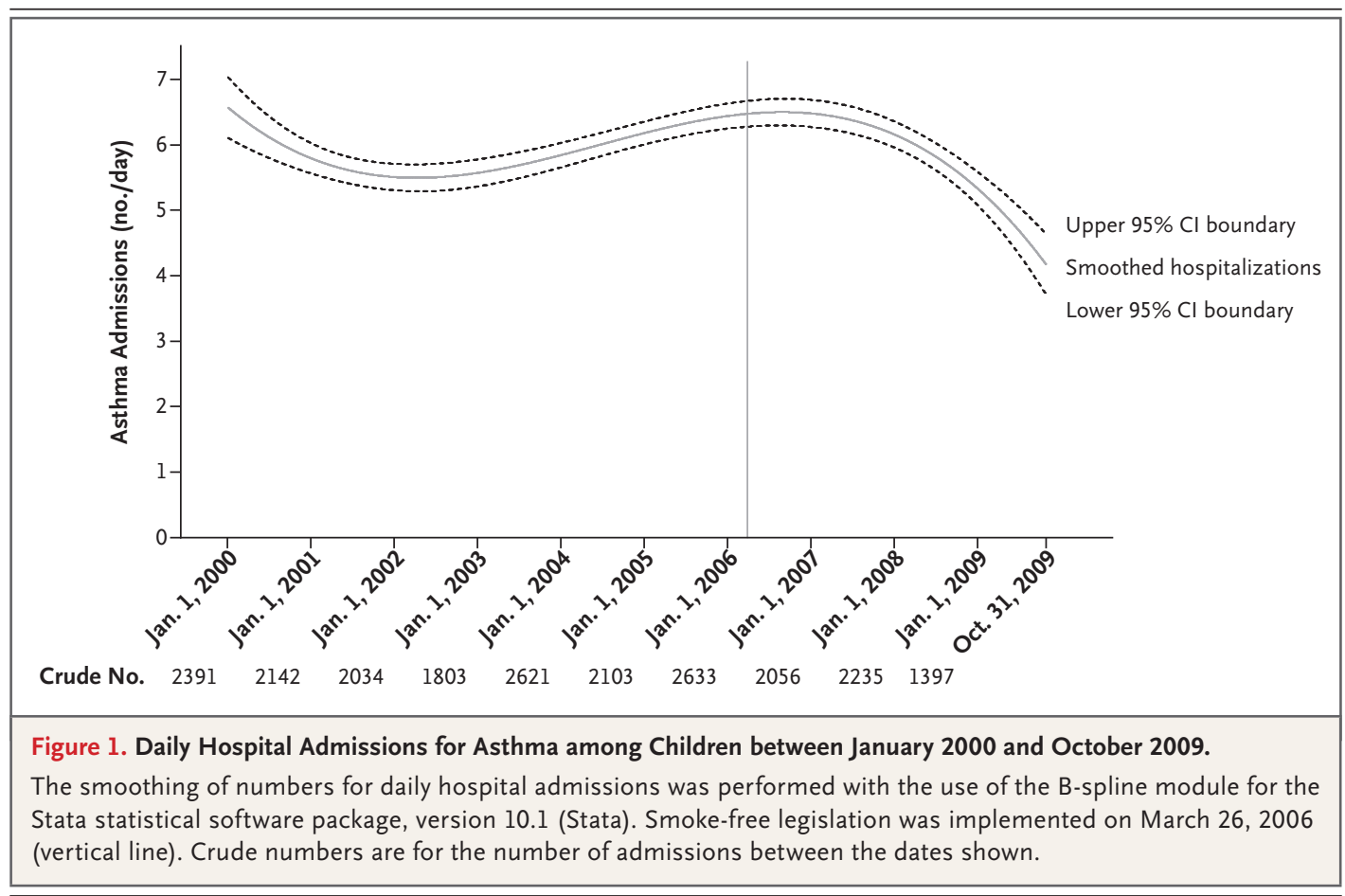

\section{STATISTICAL ANALYSIS}

Our primary analyses examined hospital admissions for asthma from January 2000 through October 2009. The analyses were restricted to children who were younger than 15 years of age at the time of their admission to the hospital for asthma. We determined the frequency of admissions each month in subgroups according to age group, sex, quintile of socioeconomic status, and urban or rural residence. Population counts in each of these subgroups, for each month, were estimated by linear extrapolation of midyear population estimates for data zones obtained from the Scottish 2001 census and published by the General Register Office for Scotland. The model allowed for the detection of an underlying trend in incidence rates throughout the study period and of a change in this trend as of the date on which the smoke-free legislation was implemented. The model was adjusted for age group, sex, quintile of socioeconomic status, urban or rural residence, month, and year. An offset term accounted for different population sizes and the number of days in each month. We extended the model to include interaction terms in order to test for differences in the change in incidence trend after implementation of the legislation within subgroups of the population (after allow- ing for different trends before implementation of the legislation) - specifically, subgroups defined on the basis of age group, sex, quintile of socioeconomic status, urban or rural residence, and region. Our analyses were repeated for the composite outcome of asthma events (hospital admissions and deaths before admission to the hospital).

\section{RESULTS}

\section{ADMISSIONS FOR ASTHMA}

There were 21,415 hospital admissions for asthma during the study period. Figure 1 shows the smoothed curves for daily numbers of admissions for asthma over the course of the study period. Before implementation of the legislation, there was a mean increase in admissions for asthma of $5.2 \%$ per year ( $95 \%$ confidence interval [CI], 3.9 to 6.6) relative to the rate at baseline, in January 2000. After implementation of the legislation, there was a reduction in the annual rate of $18.2 \%$ relative to the rate on March 26, 2006 ( $95 \%$ CI, 14.7 to $21.8 ; \mathrm{P}<0.001$ ), resulting in a net reduction in asthma admissions after implementation of the legislation of $13.0 \%$ per year $(95 \%$ CI, 10.4 to 15.6). After adjustment for the potential confounding effects of sex, age group, urban 


\begin{tabular}{|c|c|c|c|c|}
\hline Subgroup & $\begin{array}{c}\text { Annual } \\
\text { Change before } \\
\text { Legislation }\end{array}$ & $\begin{array}{c}\text { Annual } \\
\text { Change after } \\
\text { Legislation } \\
\text { percent }(95 \% \mathrm{Cl})\end{array}$ & $\begin{array}{l}\text { Net Annual } \\
\text { Change after } \\
\text { Legislation }\end{array}$ & P Value' \\
\hline Sex & & & & 0.75 \\
\hline Male & $4.1(2.7$ to 5.5$)$ & $-19.9(-23.7$ to -16.1$)$ & $-15.8(-18.6$ to -13.0$)$ & \\
\hline Female & $5.0(3.1$ to 6.8$)$ & $-18.8(-23.6$ to -14.1$)$ & $-13.9(-17.4$ to -10.4$)$ & \\
\hline Age group & & & & 0.42 \\
\hline Preschool & $0.6(-0.9$ to 2.1$)$ & $-18.4(-22.4$ to -14.3$)$ & $-17.7(-20.8$ to -14.7$)$ & \\
\hline School-age & 9.1 (7.4 to 10.8$)$ & $-20.8(-25.1$ to -16.6$)$ & $-11.8(-14.8$ to -8.7$)$ & \\
\hline Quintile of socioeconomic status & & & & 0.67 \\
\hline 1 (affluent) & $0.4(-2.4$ to 3.3$)$ & $-15.9(-23.9$ to -8.1$)$ & $-15.6(-21.5$ to -9.6$)$ & \\
\hline 2 & $5.7(2.9$ to 8.5$)$ & $-19.8(-27.0$ to -12.6$)$ & $-14.1(-19.4$ to -8.9$)$ & \\
\hline 3 & 3.7 (1.1 to 6.2$)$ & $-20.5(-27.2$ to -13.8$)$ & $-16.8(-21.8$ to -11.8$)$ & \\
\hline 4 & $4.8(2.3$ to 7.3$)$ & $-17.3(-23.6$ to -10.9$)$ & $-12.5(-17.1$ to -7.8$)$ & \\
\hline 5 (deprived) & $6.1(4.0$ to 8.3$)$ & $-22.4(-27.9$ to -16.8$)$ & $-16.2(-20.3$ to -12.1$)$ & \\
\hline Area & & & & 0.82 \\
\hline Urban & $4.7(3.3$ to 6.0$)$ & $-19.2(-22.8$ to -15.6$)$ & $-14.6(-17.2$ to -11.9$)$ & \\
\hline Rural & 3.9 (1.9 to 5.9$)$ & $-20.0(-25.2$ to -14.8$)$ & $-16.0(-19.9$ to -12.2$)$ & \\
\hline Region & & & & 0.98 \\
\hline Southwest & 3.7 (2.2 to 5.2$)$ & $-16.0(-20.0$ to -12.1$)$ & $-12.3(-15.2$ to -9.4$)$ & \\
\hline Southeast & $7.3(5.2$ to 9.3$)$ & $-23.0(-28.2$ to -17.7$)$ & $-15.7(-19.4$ to -11.8$)$ & \\
\hline North & $2.6(0.9$ to 4.3$)$ & $-17.9(-22.3$ to -13.5$)$ & $-15.3(-18.6$ to -12.0$)$ & \\
\hline
\end{tabular}

* The annual change before legislation was the change relative to the rate at baseline, in January 2000. The annual change after legislation was the change relative to the rate on March 26, 2006 - the date on which the smoke-free legislation was implemented. Temporal trends were adjusted for sex, urban or rural area, and quintile of socioeconomic status.

$\uparrow$ The $\mathrm{P}$ values were calculated with the use of a likelihood-ratio test to determine whether the additional change differed significantly according to subgroup.

or rural residence, and quintile of socioeconomic status, admissions for asthma before implementation of the legislation increased by a mean of $4.4 \%$ per year $(95 \%$ CI, 3.3 to 5.5$)$ relative to the rate in January 2000. After implementation of the legislation, there was a reduction of $19.5 \%$ (95\% CI, 16.5 to $22.4 ; \mathrm{P}<0.001$ ) relative to the rate on March 26, 2006, resulting in a net reduction in admissions for asthma of $15.1 \%$ per year $(95 \%$ CI, 12.9 to 17.2 ).

\section{ANALYSIS ACCORDING TO SUBGROUPS}

Of the 21,415 admissions for asthma, 11,796 (55.1\%) occurred among preschool children and 9619 (44.9\%) among school-age children. The trends before the legislation varied according to age group, with a mean annual increase of $9.1 \%$ among preschool children, as compared with no significant change over time among school-age children (Table 1). However, the change after legislation was similar in the two groups, with a reduction of $18.4 \%$ among preschool children and $20.8 \%$ among school-age children relative to the rate on March 26, 2006 (Table 1). Therefore, there was no significant interaction with age group. Similarly, the interactions with sex, urban or rural residence, region, and quintile of socioeconomic status were all nonsignificant (Table 1). The additional change after implementation of the legislation was significant in all subgroups (Fig. 2). Only five deaths occurred over the course of the study period. Therefore, when we reran the model using all events (both admissions and deaths), the adjusted additional change was almost identical to that obtained in the original model, which was based on admissions alone. 
Before implementation of the legislation, asthma events increased by a mean of $4.4 \%$ per year $(95 \%$ CI, 3.3 to 5.6) relative to the rate in January 2000. After implementation, there was a reduction of $19.5 \%$ ( $95 \%$ CI, 16.5 to 22.4 ) relative to the rate on March 26, $2006(\mathrm{P}<0.001)$, resulting in a net reduction in asthma events of $15.1 \%$ per year (95\% CI, 12.9 to 17.2).

\section{DISCUSSION}

Our study shows that after the introduction of comprehensive smoke-free legislation, there was a reduction in the incidence of asthma among people who did not have occupational exposure to environmental tobacco smoke. Our analysis was limited to data on children; the reduction in the incidence of asthma was observed among both preschool and school-age children.

Previous investigations of the health benefits of comprehensive smoke-free legislation have focused primarily on the incidence of cardiovascular disease. There are now a number of studies showing a reduction in the incidence of coronary events after the introduction of legislation..$^{13,14}$ The Scottish smoke-free legislation has been successful in reducing exposure to environmental tobacco smoke in public places, such as bars, ${ }^{9,10}$ resulting in fewer respiratory symptoms among workers in bars. ${ }^{11} \mathrm{~A}$ recent study showed that there was a nonsignificant $2 \%$ reduction in overall admissions for asthma after citywide smoking restrictions were instituted in Toronto. ${ }^{15}$ However, restaurants were exempt from the restrictions, and the study included adults whose exposure was reduced as a result of workplace bans on smoking. In Arizona, overall admissions for asthma have also fallen since the implementation of restrictions on smoking in public places, with the greatest reductions observed in counties that had no preexisting partial bans. ${ }^{16}$ The Arizona study also included adults who were protected from workplace exposure after the legislation.

Before implementation of the Scottish legislation, there was concern that it might result in the transfer of smoking activity to homes, leading paradoxically to an increase in exposure to environmental tobacco smoke among children. Studies of exposure among both adults ${ }^{17}$ and children ${ }^{4}$ have shown no evidence of displacement of smoking to the home; rather, the legis-

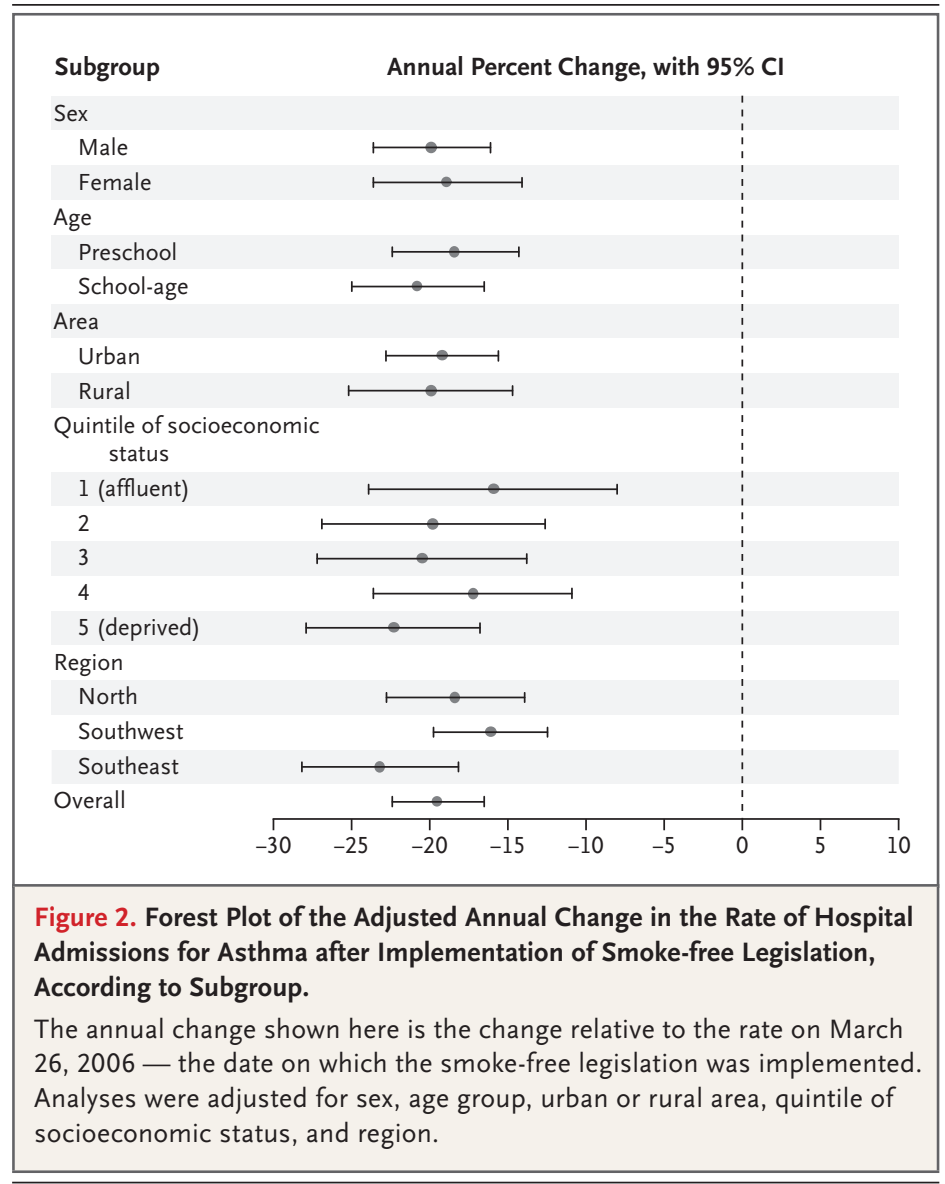

lation has been followed by an increase in voluntary restrictions in the home. ${ }^{12}$ Household smoking restrictions reduce the exposure of children to environmental tobacco smoke, irrespective of whether their own parents smoke. ${ }^{18}$ Hence, the overall exposure of children to environmental tobacco smoke, measured objectively with the use of salivary cotinine concentrations, has fallen since the implementation of the Scottish legislation. $^{4}$

There is substantial evidence of an association between exposure to environmental tobacco smoke and the risk of asthma. Exposure to environmental tobacco smoke increases the risk of asthma, and among those with asthma, it confers a predisposition to a worse prognosis, including an accelerated decline in lung function, more frequent exacerbations, more severe symptoms, impairment of the quality of life, and a diminished therapeutic response to corticosteroids. ${ }^{6}$ In a meta-analysis, the pooled estimate of the relative risk of ever having asthma as a result 
of exposure to environmental tobacco smoke was 1.48 (95\% CI, 1.32 to 1.65), the relative risk of current asthma was 1.25 (95\% CI, 1.21 to 1.30), and the relative risk of a new diagnosis of asthma was 1.21 (95\% CI, 1.08 to 1.36$){ }^{7}$ The deleterious effects of exposure to environmental tobacco smoke are greater among children than among adults, since children have smaller bodies, a higher baseline respiratory rate, and smaller airways. ${ }^{7}$ Preschool children are more likely to be exposed to environmental tobacco smoke in their homes than in public places. ${ }^{19}$ In contrast, school-age children spend less time with their parents and more time outside their homes and may themselves start smoking. Among children in Scotland, self-reported exposure to environmental tobacco smoke in public places has fallen since implementation of the legislation. ${ }^{18}$ In the Scottish Schools Adolescent Lifestyle and Substance Use Survey (SALSUS), the prevalence of smoking among 13-year-old boys fell from 5\% in February 2004 to 3\% in February 2007.3 The corresponding figures for girls were $7 \%$ and $4 \%$. We conducted a subgroup analysis with data from preschool and school-age children to determine whether the effect of the legislation differed according to age group.

In our study, we used data from all regions of Scotland, and the results were consistent across the regions. Therefore, the results cannot be attributed to changes in hospital catchment areas. We did not have data on Scottish children who were admitted to hospitals outside Scotland during the study period, but these admissions were probably few in number, and there is no reason to expect that there would have been a systematic bias over time. Our study included only asthma exacerbations that were severe enough to require admission to the hospital. We did not have access to data on less severe exacerbations of asthma that did not require hospitalization, but we are unaware of any systematic change over time in the threshold for hospital admissions for asthma. We cannot determine whether the reduction in hospital admissions was a result of the prevention of asthma exacerbations that would otherwise have occurred or a reduction in the severity of the exacerbations that did occur. The decrease in admissions was not due to an increase in the incidence of deaths before arrival at the hospital. We did not have access to information on smoking status at the individual level or on measures of the level of exposure to environmental tobacco smoke. Therefore, we cannot determine the extent to which the observed reduction in asthma was due to reduced exposure to environmental tobacco smoke in the home, reduced exposure to environmental tobacco smoke in public places, or a reduction in active smoking among school-age children. As with any observational study, there may have been other interventions that occurred during the period studied. However, we are not aware of any national educational campaigns, changes in health care delivery or clinical management, or changes in other exposures, such as air pollution, that coincided with the date on which the legislation was introduced. Awareness of asthma may have increased over time, but it is unlikely that there was a stepwise change in the awareness of asthma at the time the legislation was introduced. Asthma may have been misclassified as infection in the case of some hospital admissions, but again, there is no reason to suspect that there was a systematic error as a result of a change in the percentage of misclassified cases after implementation of the legislation.

In conclusion, our study showed that there was a reduction in the rate of hospitalizations for childhood asthma after the introduction of legislation to make public places smoke-free, suggesting that the benefits of such legislation can extend to populations other than those with occupational exposure to environmental tobacco smoke.

Supported by a project grant from NHS Health Scotland.

Disclosure forms provided by the authors are available with the full text of this article at NEJM.org.

\section{REFERENCES}

1. Anderson HR, Gupta R, Strachan DP, Limb ES. 50 Years of asthma: UK trends from 1955 to 2004. Thorax 2007;62:8590.

2. Scotland's people: annual report: results from 2007/2008 Scottish Household Survey. Edinburgh: Scottish Government,
2009. (Accessed August 23, 2010, at http:// www.scotland.gov.uk/Resource/ Doc/282618/0085510.pdf.)

3. Black C, MacLardie J, Maihot J, Murray L, Sewel K. Scottish Schools Adolescent Lifestyle and Substance Use Survey (SALSUS). National report 2008. Edin- burgh: Information Services Division, 2009. (Accessed August 23, 2010, at http:// www.drugmisuse.isdscotland.org/ publications/abstracts/salsus.htm.)

4. Akhtar PC, Currie DB, Currie CE, Haw SJ. Changes in child exposure to environmental tobacco smoke (CHETS) study af- 
ter implementation of smoke-free legislation in Scotland: national cross sectional survey. BMJ 2007;335:545.

5. Gergen PJ, Fowler JA, Maurer KR, Davis WW, Overpeck MD. The burden of environmental tobacco smoke exposure on the respiratory health of children 2 months through 5 years of age in the United States: Third National Health and Nutrition Examination Survey, 1988 to 1994. Pediatrics 1998;101(2):e8.

6. Baena-Cagnani CE, Gómez RM, Baena-Cagnani R, Canonica GW. Impact of environmental tobacco smoke and active tobacco smoking on the development and outcomes of asthma and rhinitis. Curr Opin Allergy Clin Immunol 2009;9:13640.

7. Vork KL, Broadwin RL, Blaisdell RJ. Developing asthma in childhood from exposure to secondhand tobacco smoke: insights from a meta regression. Environ Health Perspect 2007;115:1394-400.

8. Office of Environmental Health Hazard Assessment. Health effects of exposure to environmental tobacco smoke: final report. Sacramento: California Environmental Protection Agency, 2005. (Accessed August 23, 2010, at http://www .oehha.org/air/environmental_ tobacco/2005etsfinal.html.)
9. Semple S, Creely KS, Naji A, Miller BG, Ayres JG. Secondhand smoke levels in Scottish pubs: the effect of smoke-free legislation. Tob Control 2007;16:127-32.

10. Semple S, Maccalman L, Naji AA, et al. Bar workers' exposure to second-hand smoke: the effect of the Scottish smokefree legislation on occupational exposure. Ann Occup Hyg 2007;51:571-80.

11. Ayres JG, Semple S, MacCalman L, et al. Bar workers' health and environmental tobacco smoke exposure (BHETSE): symptomatic improvement in bar staff following smoke-free legislation in Scotland. Occup Environ Med 2009;66:33946.

12. Akhtar PC, Haw SJ, Currie DB, Zachary $\mathrm{R}$, Currie $\mathrm{CE}$. Smoking restrictions in the home and secondhand smoke exposure among primary schoolchildren before and after introduction of the Scottish smoke-free legislation. Tob Control 2009;18:409-15.

13. Pell JP, Haw S, Cobbe S, et al. Smokefree legislation and hospitalizations for acute coronary syndrome. N Engl J Med 2008;359:482-91.

14. Meyers DG, Neuberger JS, He J. Cardiovascular effect of bans on smoking in public places: a systematic review and meta-analysis. J Am Coll Cardiol 2009;
54:1249-55. [Erratum, J Am Coll Cardiol 2009;54:1902.]

15. Naiman A, Glazier RH, Moineddin R. Association of anti-smoking legislation with rates of hospital admission for cardiovascular and respiratory conditions. CMAJ 2010;182:761-7.

16. Herman PM, Walsh ME. Hospital admissions for acute myocardial infarction, angina, stroke and asthma after implementation of Arizona's comprehensive statewide smoking ban. Am J Public Health 2010 May 13 (Epub ahead of print).

17. Haw SJ, Gruer L. Changes in exposure of adult non-smokers to secondhand smoke after implementation of smokefree legislation in Scotland: a national cross-sectional survey. BMJ 2007;335:549. 18. Akhtar PC, Haw SJ, Levin KA, Currie DB, Zachary R, Currie CE. Socioeconomic differences in second-hand smoke exposure among children in Scotland after introduction of the smoke-free legislation. J Epidemiol Community Health 2010;64: 341-6.

19. Ashley MJ, Ferrence R. Reducing children's exposure to environmental tobacco smoke in homes: issues and strategies. Tob Control 1998;7:61-5.

Copyright (c) 2010 Massachusetts Medical Society.

APPLY FOR JOBS ELECTRONICALLY AT THE NEJM CAREERCENTER

Physicians registered at the NEJM CareerCenter can apply for jobs electronically using their own cover letters and CVs. You can keep track of your job-application

history with a personal account that is created when you register

with the CareerCenter and apply for jobs seen online at our Web site. Visit NEJMjobs.org for more information. 